\title{
The young infant diaphragm: What goes up should come down
}

\author{
Ronald K. Woods, MD, PhD
}

From the Division of Pediatric Cardiothoracic Surgery, Department of Surgery, Medical College of Wisconsin; and Herma Heart Center, Children's Hospital of Wisconsin, Milwaukee, Wis.

Disclosures: Author has nothing to disclose with regard to commercial support.

Received for publication July 10, 2017; accepted for publication July 14, 2017; available ahead of print Aug 18, 2017.

Address for reprints: Ronald K. Woods, MD, PhD, FACS, FAAP, Department of Surgery, Medical College of Wisconsin, Division of Pediatric Cardiothoracic Surgery, Children's Hospital of Wisconsin, 9000 W Wisconsin Ave, MS B 730, Milwaukee, WI 53226 (E-mail: rwoods@chw.org).

J Thorac Cardiovasc Surg 2017;154:1722

$0022-5223 / \$ 36.00$

Copyright (C) 2017 by The American Association for Thoracic Surgery

http://dx.doi.org/10.1016/j.jtcvs.2017.07.026

In this issue of the Journal, Floh and colleagues ${ }^{1}$ report their 10-year experience with post-cardiac surgical diaphragm dysfunction in 161 patients, or $2.5 \%$ of their overall surgical cohort. Diaphragm plication was done in only 30 cases; these patients tended to be younger and were more likely to have undergone cardiac repair with deep hypothermic circulatory arrest. Plication within 7 days of diagnosis (early in their terms) in 16 cases was associated with shorter overall intensive care unit and hospital stays relative to the group with later plication, and both groups demonstrated similar postplication stays. Given the numerous reports on diaphragm dysfunction and plication, the reader may wonder what unique information the report of Floh and colleagues ${ }^{1}$ provides. Despite the clearly outlined limitations, this report quantifies the substantial impact on value of earlier plication: early versus late plication was associated with a much shorter duration of positive-pressure ventilation (10 vs 30 days); shorter intensive care unit stay (20 vs 35 days); and shorter overall hospital stay (30 vs 57 days). Even with some degree of inevitable bias, such as possibly delaying surgery for sicker patients, these dramatic differences should translate into reduced cost. Given the simplicity, effectiveness, and low complication profile of plication (potential long-term chest wall morbidity not considered, but likely low), early plication should substantially improve the overall value of care.

Complicating this very simple message is the fact that these outcome measures were either the same or slightly better in 128 patients with no plication. So, if plication is needed, do it early-but use your best judgment to determine which patients need plication. What should factor into this judgment? I agree with Floh and colleagues ${ }^{1}$ that young age or small size (neonate or young infant) and overall deconditioning favor plication and that deep hypothermic circulatory arrest, although strongly associated with plication, is not likely a reliable means of predicting need for plication. In their cohort, $60 \%$ of the patients with plication had paralysis (not just paresis), versus $29 \%$ of the patients without plication. Also,

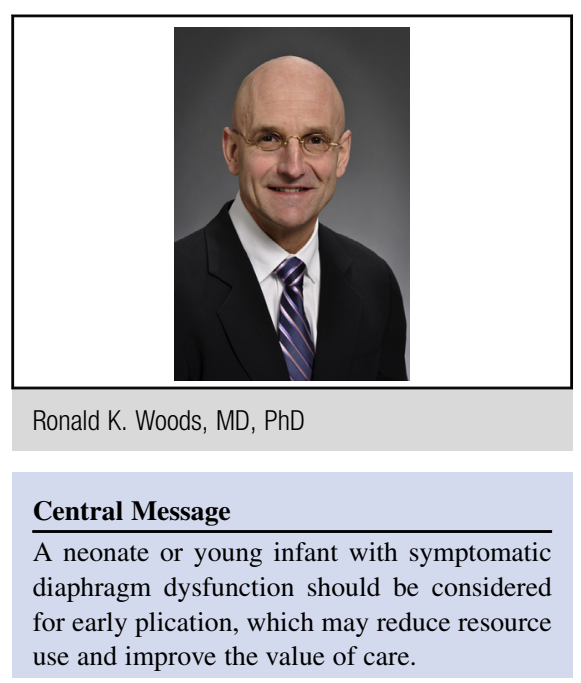

See Article page 1715 .

42 neonates in this study did not undergo plication. At my institution, it would be exceedingly uncommon for a neonate with an elevated hemidiaphragm to not undergo plication. This applies to the patient with single-ventricle circulation as well. I suspect many of the neonates without plication had diagnoses of paresis and did not have marked elevation of the diaphragm without positive-pressure ventilation. Although we use ultrasound as well as fluoroscopy and note paresis versus paralysis at my institution, we agree with the physiologically based argument of Floh and colleagues ${ }^{1}$ that the presence of symptoms and degree of volume loss are the more important variables, rather than paresis versus paralysis per se. Paresis does not ensure prompt recovery of function and is a diagnosis of questionable merit in the young patient with symptoms (as an aside, the best reference that I could find for interobserver reliability of ultrasound of the diaphragm did not specifically evaluate neonates ${ }^{2}$ ). In other words, for a young patient with clinically relevant symptoms that are not due to some other cause, the diaphragm that comes up should come down. Plicate early, and improve the value of care.

\section{References}

1. Floh AA, Zafurallah I, MacDonald C, Honjo O, Fan C-P, Laussen PC. The advantage of early plication in children diagnosed with diaphragm paresis. J Thorac Cardiovasc Surg. 2017; 154:1715-21.e4.

2. El-Halaby H, Adbel-Hady H, Alsawah G, Abdelrahman A, El-Tahan H. Sonographic evaluation of diaphragmatic excursion and thickness in healthy infants and children. J Ultrasound Med. 2016;35:167-75. 